\title{
NGHIÊN CỨU CHỈ ĐİNH MỔ LẤY THAI NHÓM I THEO PHÂN LOẠI CỦA ROBSON TẠI BỆNH VIỆN PHỤ SẢN HẢI PHÒNG
}

\section{TÓM TẮT}

Hiện nay, tỷ lệ mổ lấy thai trên thế giới đang có xu hướng gia tăng và đang dân trở thành một vấn đề sức khỏe toàn câu. Mục tiêu: Nghiên cứu chỉ định mổ lấy thai nhóm 1 theo phân loại của Robson (con so, ngôi đầu, $\geq 37$ tuần, chuyển dạ tự nhiên) tại Bệnh viện Phụ sản Hải Phòng. Đối tượng và phương pháp nghiên cứu: 3457 thai phụ đến nhập viện và sinh tại Bệnh viện Phụ sản Hải Phòng. Kết quả: Tỉ lệ mổ lẩy thai của nhóm 1 là $36,65 \%$, góp phân vào tỉ lệ mổ lấy thai chung là $10,67 \%$. Nhóm nguyên nhân chuyển da ngưng tiển triển và mổ lấy thai do thai và phần phụ chiếm tỉ lệ cao nhất là $34,15 \%$ và $37,4 \% \%$, góp phân vào tỉ lệ mổ lấy thai chung lần lượt là $12,51 \%$ và 13,7\%. Các nguyên nhân bất thường về phía mẹ, bất cân xứng đâu châu hay cớn co cường tính chiếm tỉ lề thấp hơn lần lượt là 6,78\%; 7,59\% và $14,09 \%$. Kết Iuân: Tỉ lệ mổ lấy thai của nhóm 1 là 36,65\%, góp phần vào tỉ lệ mô lấy thai chung là $10,67 \%$. Cân có can thiệp sâu hơn vào nhóm 1 để làm giảm tỉ lệ mổ lấy thai.

Tư khóa: mổ lấy thai, con so, tỉ lệ

\section{SUMMARY}

RESEARCH INDICATIONS FOR CESAREAN SECTION GROUP I BY ROBSON'S CLASSIFICATION AT HAI PHONG HOSPITAL OF GYNECOLOGY AND OBSTETRICS HOSPITAL

Nowadays, the rate of cesarean section in the world is increasing and is increasing gradually becoming a global health problem. Objective: To study the indications for caesarean section group 1 according to Robson's classification (first-born, cephalic presentation, $\geq 37$ weeks, spontaneous labor) at Hai Phong Obstetrics and Gynecology Hospital. Research object and method: 3457 pregnant women came to the hospital and gave birth at Hai Phong Hospital of Obstetrics and Gynecology. Result: Rate of the cesarean section group 1 was $36.65 \%$, contributing to the overall cesarean section rate of $10.67 \%$. Group of causes of labor stopping progress and cesarean section due tofetus and appendages of the fetus accounted for the highest rates of $34.15 \%$ and $37.4 \% \%$, contributing to the overall cesarean section rate was $12.51 \%$ and $13.7 \%$, respectively. Abnormal causes on the mother's part, pelvic head asymmetry or intense contractions accounted for $6.78 \%$ lower, respectively; $7.59 \%$ and $14.09 \%$. Conclusion: Rate

*Bệnh viện Phụ sản Hải Phòng

Chịu trách nhiệm chính: Vũ Văn Tâm

Email: Drvuvantam@gmail.com

Ngày nhận bài: 13.9.2021

Ngày phản biện khoa học: 10.11.2021

Ngày duyệt bài: 19.11.2021

\section{Vũ Văn Tâm*, Lưu Vũ Dũng*}

ofcaesarean section group 1 was $36.65 \%$, contributing to the overall caesarean section rate was $10.67 \%$. Requireddeeper intervention in group 1 to reduce the rate of cesarean section.

Keywords; cesarean section, rate, first-born.

\section{I. ĐĂT VẤN ĐỀ}

Hiện nay, tỷ lệ mổ lấy thai trên thế giới đang có xu hướng gia tăng và nó đang dần trở thành một vấn đề sức khỏe toàn cầu[1]. Theo các báo cáo của Hoa Kỳ đã được công bố, tỷ lệ mổ lấy thai trung bình năm 2008 là $32,8 \%$ và duy trì tỷ lệ này đến năm 2013 là 32,7\%[2,3]. Còn tại Braxin, tỷ lệ này năm 2010 là 41,3\%. Tại Việt Nam, tỷ lệ mổ lấy thai đang có xu hướng ngày càng gia tăng, theo số liệu đã công bố tại Bệnh viện phụ sản Trung ương tỷ lệ mổ lấy thai năm 2008 là 45,3\%. Còn tại bệnh viện Từ Dũ tỷ lệ này năm 2008 là 47,2\%, năm 2015 vẫn đang duy trì ở mức cao là $47,6 \%$ [4].

Theo như nghiên cứu của tác giả Lê Quang Thanh năm 2015 tại Bênh viện Từ dũ cho thây: chiến lược then chốt để có tỳ lệ mổ lấy thai hợp lý là can thiệp vào nhóm 1 theo nhóm phân loại của Robson (con so, ngôi đầu, > 37 tuần, chuyển dạ tự nhiên) [4]. Chính vì lý do đó, chúng tôi tiến hành nghiên cứu "Nghiên cứu chì định mổ lấy thai nhóm 1 theo phân loại của Robson tại Bệnh viện Phụ sản Hải Phòng".

II. ĐỐI TƯỢNG VÀ PHƯƠNG PHÁP NGHIÊN CỨU

2.1. Đối tượng nghiên cứu. Các hồ sơ thai phụ tới nhập viện và sinh tại Bệnh viện Phụ sản Hải Phòng.

- Thời gian nghiên cứu: từ 01/01/2019 đến tháng 30/06/2019.

- Tiêu chuân lựa chon:

Hồ sơ bệnh án của tất cả các thai phụ tới nhập viện và sinh tại Bệnh viện Phụ sản Hải Phòng.

- Tiêu chuấn loại trù:

+ Hồ sơ xuất viện hoặc chuyển viện khi chưa sinh con.

+ Hồ sơ sinh thường và mổ lấy thai từ nơi khác chuyển đến vì các nguyên nhân khác.

+ Hồ sơ bệnh án không ghi chép đủ các thông tin cần thiết cho nghiên cứu.

\subsection{Phương pháp nghiên cứu}

2.2.1. Thiết kế nghiên cứu: Mô tả hồi cứu

2.2.2. Cỡ mẫu nghiên cứu: Dựa vào công thức tính cõ mẫu: 
Trong đó:

$$
n=Z_{\left(1-\frac{\alpha}{2}\right)}^{2} \frac{P(1-P)}{d^{2}}
$$

- n: cõ mẫu - ${ }_{\left(1-\frac{\alpha}{2}\right)}^{2}$ : khoảng tin cậy $=1,96$

- $P=0,1$ (tỷ lệ mổ lấy thai nhốm 1 tại Bệnh viện Từ Dũ năm 2015)

- d: độ chính xác tuyệt đối mong muốn, chọn $d=0,01$.

Tính ra $\mathrm{n}=3457,44$. Lấy mẫu là 3457 hồ sơ tới sinh tại Bệnh viện Phụ sản Hải Phòng.

\subsubsection{Chỉ số nghiên cứu:}

III. KẾT QUẢ NGHIÊN CỨU

Tỉ lệ mổ lây thai chung và góp phân tỉ lệ mổ lấy thai nhóm 1

Bảng 3.1. Ti lệ mổ lấy thai chung và góp phần tỉ lệ mổ lây thai nhóm 1

\begin{tabular}{|c|c|c|c|c|c|c|c|}
\hline \multirow[t]{2}{*}{$\begin{array}{c}\text { Tổng số mẫu } \\
\text { nghiên cứu }\end{array}$} & \multicolumn{2}{|c|}{$\begin{array}{c}\text { Tỷ lệ mổ lấy } \\
\text { thai }\end{array}$} & \multicolumn{2}{|c|}{ Kích cõ nhóm 1} & \multicolumn{2}{|c|}{$\begin{array}{c}\text { Số sản phụ mố } \\
\text { lấy thai trong } \\
\text { nhóm } 1\end{array}$} & \multirow[t]{2}{*}{$\begin{array}{l}\text { Góp phân } \\
\text { nhóm } 1 \text { vào tỉ } \\
\text { lệ MLT chung }\end{array}$} \\
\hline & $\mathbf{n}$ & Tỉ lệ \% & $\mathbf{n}$ & Tỉ lệ \% & $\mathbf{n}$ & Tỉ lệ \% & \\
\hline 3457 & 1724 & 49,86 & 1007 & 29,13 & 369 & 36,65 & $10,76 \%$ \\
\hline
\end{tabular}

Nhận xét: Trong 3457 trường hợp nghiên cứu tỉ lệ mố lấy thai tại Bệnh viện là 49,86\%. Kích cỡ nhóm 1 là $29,13 \%$. Trong đó, mổ lấy thai chiếm 36,65\%, góp phần của nhóm 1 vào mổ lấy thai chung là $10,67 \%$.

Tỉ lệ mố lấy thai theo các nhóm nguyên nhân

Bảng 3.2. Chỉ định mổ lấy thai trong các nhóm nguyên nhân

\begin{tabular}{|c|c|c|c|}
\hline Chỉ định & $\mathbf{n}=\mathbf{3 6 9}$ & Tỉ lệ \% & $\begin{array}{c}\text { Góp phân tỉ lệ MLT trong } \\
\text { nhóm 1(36,65\%) }\end{array}$ \\
\hline Chuyển dạ ngừng tiến triến & 126 & 34,15 & 12,51 \\
\hline Do thai, phần phụ thai & 138 & 37,4 & 13,7 \\
\hline Bất thường phía mẹ & 25 & 6,78 & 2,48 \\
\hline Bất cân xứng đầu chậu, cơn co cường tính & 28 & 7,59 & 2,78 \\
\hline Nguyên nhân khác & 52 & 14,09 & 5 \\
\hline
\end{tabular}

Nhận xét: Nguyên nhân mố lấy thai do chuyển dạ ngừng tiến triển và do thai, phần phụ của thai chiếm tỉ lệ cao nhất lần lượt là $34,15 \%$ và $37,4 \%$; góp phần vào tỉ lệ mổ lấy thai chung của nhóm lần lượt là $12,51 \%$ và $13,7 \%$. Nhóm thấp nhất là nhóm nguyên nhân bất thường về phía me chiếm tỉ lệ $6,78 \%$ và góp phần vào tỉ lệ mổ lấy thai chung là $2,48 \%$.

Biến chứng trong và sau mổ lấy thai

Bảng 3.3. Tỉ lệ tai biến trong mổ và biến chứng sau mổ lấy thai

\begin{tabular}{|c|c|c|}
\hline $\begin{array}{c}\text { Tai biến, biến } \\
\text { chứng }\end{array}$ & $\begin{array}{c}\text { Tống số } \\
\mathbf{n = 3 6 9}\end{array}$ & $\begin{array}{c}\text { Tỉ lệ } \\
\mathbf{\%}\end{array}$ \\
\hline \multicolumn{2}{|c|}{ Tai biến trong mố } \\
\hline Không & 352 & 95,39 \\
\hline Chảy máu & 6 & 1,63 \\
\hline Đờ tữ cung & 11 & 2,98 \\
\hline \multicolumn{2}{|c|}{ Biến chứng sau mố } \\
\hline Không & 367 & 99,46 \\
\hline Đờ tữ cung sau mố & 2 & 0,54 \\
\hline $\begin{array}{c}\text { Viêm niêm mạc tử } \\
\text { cung sau mổ }\end{array}$ & 0 & 0 \\
\hline
\end{tabular}

Nhận xét: Tỉ lệ chảy máu trong cuộc mổ chiếm $1,63 \%$ các trường hợp, có 11 trường hợp bị đờ tử cung chiếm 2,98\%. Tuy nhiên, sau mổ được đánh giá chỉ có 2 trường hợp có xuất hiện đờ tử cung thứ phát sau mổ chiểm tỉ lệ $0,54 \%$; còn lại 99,46\% các trường hợp là ổn định sau mố.

\section{BÀN LUÂ̂N}

Tỉ lệ mổ lây thai chung và góp phân tỉ lệ mổ lấy thai nhóm 1. Theo kết quả nghiên cứu ở Bảng 3.1 cho thấy tổng số bệnh nhân thuộc nhóm 1là 1007 trường hợp chiếm tỉ lệ 29,13\% trong tổng số 2457 trường hợp đến đẻ tại Bệnh viện Phụ sản Hải Phòng. Tỉ lệ mổ lấy thai con so trong nghiên cứu này này là $36.65 \%$ tương 
đương với các nghiên cứu của Vương Tiến Hòa năm 2002 tại Bệnh viện Phụ sản Trung ương là $33,44 \%$ [5]. So với kểt quả nghiên cứu của tác giả Lê Quang Thanh năm 2016 tại Bệnh viện Từ Dũ nghiên cứu trên 5409 trường hợp mang thai cho thấy: nhóm 1 chiếm tỉ lệ $26,94 \%$, trong đó tỉ lệ mổ lấy thai của nhóm 1 là 39,05\%, góp phần vào tỉ lệ mổ lấy thai chung là $10,52 \%[4]$. Chúng tôi nhận thấy tỉ lệ mổ lấy thai chung của Bệnh viện Phụ sản Hải Phòng là cao chiếm 49,86\% các trường hợp đến sinh nhưng về tỉ lệ mổ lấy thai ở nhóm con so chỉ có $10,67 \%$. Bênh viện Phu sản Hải Phòng và Bệnh viện Từ Dũ đều có tỉ lệ mổ lấy thai cao nằm trong xu hướng chung của thế giới hiện nay. So sánh với nghiên cứu của tác giả Robson tại Bệnh viện sản khoa Quốc gia Dublin Ireland năm 2012 cho thấy: tî lệ mổ lấy thai chung nhóm 1 là $34,8 \%$ tương đướng với nghiên cứu của chúng tôi là $36,65 \%$; kích cõ nhóm 1 là $28 \%$ cũng tương đương với chúng tôi là $29,13 \%$. Tuy nhiên tỉ lệ mổ lấy thai của nhóm 1 góp phần vào tỉ lệ mổ lấy thai chung thì nghiên cứu của chúng tổi cao hơn hẳn là 10,67\% so với 5,9\% [6].

Chỉ định mổ lấy thai theo các nhóm nguyên nhân. Theo Bảng 3.2, trong tổng số 369 trường hợp mổ lấy thai của nhóm 1 các chỉ định mổ lấy thai ở các nhóm như sau:

- Chỉ định mổ lấy thai do chuyển dạ ngừng tiến triển. Tỉ lệ mổ lấy thai do chuyển dạ ngừng tiến triển góp phần mổ lấy thai là $12,51 \%$. So sánh với tác giả Đỗ Quang Mai năm 2007 là 55,65\% [7] thì nghiên cứu của chúng tôi thấp hơn hẳn, tuy nhiên kết quả của chúng tôi tương đồng với nghiên cứu của Phạm Bá Nha tại Bệnh viện Bạch Mai năm 2008 là 12.3\% [8].

- Chỉ định mổ lấy thai do thai và phần phụ của thai. Tỉ lệ mổ lấy thai do thai và phần phự của thai chiếm tỉ lệ cao là $37,4 \%$; góp phần mổ lấy thai là $13,7 \%$. Trong nhóm nguyên nhân mổ lấy thai do thai thì thai suy chiếm tỷ lệ cao nhất. Tiếp đến là nhóm thai to có trọng lượng $>3500$ gram. Nguy cơ của một trường hợp thai to khi cho sinh qua đường âm đạo là có nguy cơ bị vỡ tử cung, kẹt vai và tổn thương đám rối thần kinh cánh tay...

- Chỉ định mổ lấy thai do bất thường về phía mẹ. Trong nhóm nguyên nhân này tỉ lệ cao nhất là do tiền sản giật, ít gặp hơn là các nguyên nhân đái tháo đường thai kì, tim mạch và các bệnh lý khác (hen phế quản, HIV...). Tỉ lệ ít gặp như vậy vì chúng ta đang nghiên cứu nhóm 1 là nhóm nguy cơ thấp, các bệnh lý này có thể phát hiện sớm trong quá trình quản lý thai kì. Chỉ có các trường hợp không được quản lý thai kì, khám và chăm sóc trước sinh đầy đủ nên khi chuyển dạ nhập viện mới phát hiện ra các bất thường về phía mẹ phải chỉ định mổ lấy thai.

- Chỉ định mổ lấy thai do bất cân xứng đầu chậu, rối loạn cơn co tử cung. Nhóm nguyên nhần này chiếm tỉ lệ thấp trong các nguyên nhân mổ lấy thai là $7,59 \%$ và góp phần vào tỉ lệ mô lấy thai chung nhóm 1 là 2,7\%. Chúng tôi nhận thấy khung chậu giới hạn chiếm đại đa số các trường hợp mổ lấy thai, tỉ lệ cớn co cường tính thấp là do những trường hợp rối loạn cơn co điều chỉnh không được mới chỉ định mổ lấy thai.

Biến chứng trong và sau mổ lấy thai. Theo kết quả nghiên cứu ở Bảng 3.3, chúng tôi thấy tỉ lệ tai biến trong các trường hợp mổ lấy thai nhóm 1 chỉ có 11 trường hợp chiếm 2,98\% có biến cố đờ tử cung, 6 trường hợp chiếm $1,63 \%$ có biến cố chảy máu ngay sau phẫu thuật, còn lại hầu hết là diễn ra an toàn với tỉ lệ là $95,39 \%$.

Tí lệ biến chứng sau mổ tại Bệnh viện Phụ sản Hải Phòng rất thấp chỉ có 2 trường hợp chiếm $0,54 \%$ đều là biến chứng đờ tử cung sau sinh. Các nghiên cứu khác đều chỉ ra rằng, biến chứng này được ghi nhận ở cả sinh thường và sinh mổ trong 24 giờ đầu sau sinh [1,9]. Đây là nỗ lực của các nhân viên y tế bệnh viện và khẳng định trình độ thầy thuốc đã được nâng cao làm giảm tỉ lệ biến chứng cho bệnh nhân xuống mức thấp nhất.

\section{KẾT LUẬN}

Tỉ lệ mổ lấy thai của nhóm là $36,65 \%$, góp phần vào tî lệ mổ lấy thai chung là $10,67 \%$. Nhóm nguyên nhân chuyển dạ ngứng tiến triển và mổ lấy thai do thai và phần phụ chiếm tỉ lệ cao nhất là $34,15 \%$ và $37,4 \% \%$, góp phần lần lượt là $12,51 \%$ và $13,7 \%$.

\section{KIẾN NGH!}

Cần có can thiệp sâu hơn vào nhóm 1 để làm giảm tỉ lệ mổ lấy thai đặc biệt ở nhóm con to và nhóm cớn co tử cung cường tính, nhóm nguyên nhân do đầu không lọt.

\section{TÀI LIÊU THAM KHẢO}

1. Betrans A,P., Torloni M.R., Zang J. et al (2016), "WHO statement on caesarean section rates", BJOG: An International Journal of Obstetrics \& Gynaecology, 123 (5), pp.667-670.

2. Nguyê̂n Thảo Quyên (2016), "Mổ lấy thai chủ động", Nội san y học sinh sản, 38, pp.19.

3. Gholitabar M., Ullman R., James D., et al (2011), "Caesarean section: summary of update NICE guidance", BMJ, 343, pp.d 7108 .

4. Lê Quang Thanh (2016), "Chiến lược giảm tỉ lệ mổ lấy thai", Hội nghị sản phụ khoa Việt Pháp lần 
thứ 16, pp.33-49.

5. Vương Tiến Hòa (2004), "Nghiên cứu chỉ đinh mổ lấy thai ở người đẻ con so tại Bệnh viện Phụ sản Trung ương năm 2002", Tạp chí nghiên cứu ỳ hoc, 21 (5), pp.79-84.

6. Robson M., Hartigan L., Murphy M., (2013), "Methods of achieving and maintaining an appropriate caesarean section rate", Best practice \& research Clinical Obstetrics \& Gynaecology, 27 (2), pp.297-308.

7. Đố Quang Mai (2007), "Nghiên cứu tình hình mổ lây thai ở sản phụ con so tại Bệnh viện Phụ sản Trung ương trong 2 năm 1996-2017", Luân vắn tốt nghiếp Thac sĩ y hoc, Trường Đai hoc $Y$ Hà Nôi

8. Phạm Bá Nha (2008), "Nghiền cứu về chỉ định mồ lấy thai tai Khoa sản Bênh viên Bach Mai năm 2008", Đề tài nghiên cứu cấp cở sở, Trường Đại hoc Y'Hà Nôii.

9. Schantz C., Ravit M., Traore A., et al (2018), "Why are caesarean section rates so high in facilities in Mali and Benin?", Sex Reprod Health 16, pp.10-14.

\title{
NỒNG Độ ACID URIC MÁU TRÊN BỆNH NHÂN BI BÊNH THẬN MẠN TẠI BỆNH VIÊ̂N C THẦNH PHỐ ĐÀ NẪNG
}

\author{
Huỳnh Thi Ngọc Ánh¹, Lê Thị Thúy ${ }^{1}$, Hồ Thị Tuyết Thu ${ }^{1}$, \\ Ngô Thị Tuyết ${ }^{1}$, Lê Thị Hà $M y^{1}$, Trần Quốc Chiến ${ }^{1}$, \\ Huỳnh Ngọc Sơnn ${ }^{2}$, Huỳnh Đức Minh ${ }^{3}$, Lâm Vĩnh Niên ${ }^{4}$.

\section{WITH CHRONIC KIDNEY DISEASE} \\ IN DA NANG C HOSPITAL
}

\section{TÓM TẮT}

Đăt vấn đề: Bênh thân mãn giảm đào thải acid uric đều làm tăng nồng đổ acid uric máu. Mục tiêu: Khảo sát sự biến thiên nồng độ acid uric trền bệnh nhân bi bênh thân mạn. Khảo sát mối liên quan và tương quan giữa nồng độ acid uric trên bệnh nhân bị bệnh thận mạn với một số đặc điểm lâm sàng và cận lâm sàng. Phương pháp: Thiết kế nghiên cứu cắt ngang, được lấy mẫu thuận tiện khảo sát 98 bệnh nhân đến khám tại Khoa Nội thận - Bệnh viện C TP Đà Nẵng được chẩn đoán bệnh thận mạn từ tháng 03/2020 đến 10/2020. Đối tượng xác định thuộc mẫu nghiên cứu được làm các xét nghiệm cần thiết cho nghiên cứu: acid uric, ure, creatinin, GFR, công thức máu. Số liêu sau khi thu thâp được xử lý bằng phần mềm thống kê y học Stata 14.0. Kết quả: Nống độ trung bình acid uric của đối tương nghiên cứu 425,0 \pm $118,1 \mu \mathrm{mol} / \mathrm{l}$ và có sự khác biệt có ý nghĩa thống kê với các giai đoạn bệnh thận mạn $(p=0,029)$. Có mối tương quan thuận mức độ trung bình có ý nghĩa thống kê giữa nồng đổ acid uric với ure, creatinin $(p<0,05)$ và có mối tương quan nghịch mức độ trung bình có ý nghĩa thống kê giữa nồng độ acid uric với GFR ( $p<$ 0,05). Kết luận: Cần thường xuyên theo dõi nông acid uric máu ở bênh nhân bênh thận mạn. GFR.

Tư khoá: acid uric,bệnh thận mạn, ure, creatinin,

\section{SUMMARY \\ BLOOD URIC ACID LEVELS IN PATIENTS}

\author{
${ }^{1}$ Trường Đại học Kỹ thuật Y-Dược Đà Nẵng \\ 2Bênh viên $C$ Thành phố Đà Nẵng \\ 3Trung tâm y tế Quận Hải Châu Thành phố Đà Nã̃ng \\ ${ }^{4}$ Đai hoc Y Dướ Thành phố Hồ Chí Minh \\ Chịu trách nhiệm chính: Lâm Vĩnh Niên \\ Email: nien@ump.edu.vn \\ Ngày nhân bài: 14.9.2021 \\ Ngày phản biên khoa hoc: 11.11.2021 \\ Ngày duyệt bài: 18.11.2021
}

Background: Chronic kidney disease reduces uric acid excretion and increases blood uric acid levels. Objectives: Investigation of variation in uric acid concentration in patients with chronic kidney disease. To investigate the relationship and correlation between uric acid levels in patients with chronic kidney disease with some clinical and subclinical. Method: This is a descriptive cross-sectional study on 98 patients, Department of Nephrology - Urology at Da Nang C Hospital from March 2020 to October 2020. Research subjects were performed tests: acid uric, ure, creatinin, GFR, blood count Collected data were handled by the medical statistical method with the support of Stata 14.0 software. Results: The average acid uric levels was $425,0 \pm 118,1 \mu \mathrm{mol} / \mathrm{l}$ and there was significant association with stage of chronic kidney disease ( $p=$ 0,029 ). There was a positive correlation of acid uric levels with ure, creatinine and negative correlation of acid uric levels with GFR $(p<0,05)$. Conclusion: Blood uric acid levels should be regularly monitored in patients with chronic kidney disease.

Keywords: acid uric, chronic kidney disease, ure, creatinin, GFR.

\section{I. ĐẶT VẤN ĐỀ}

Hiện nay bệnh thận mạn là một vấn đề sức khỏe đang được quan tâm trong y học trên thế giới vì tỷ lệ mắc bệnh ngày càng gia tăng, tăng gánh nặng chi phí điều trị và chất lượng cuộc sống giảm đáng kể. Nhiêuu nghiên cứu tại Mỹ, châu Âu, châu Á cho thây có khoảng $9-13 \%$ dân số thế giới mắc bệnh thận mạn. Tại Hoa Kỳ, tỷ lệ mắc bệnh thận mạn tăng từ năm 1988-1994 đến nẵm $1999-2004$ (12\% đến 14\%) và tỷ lệ này vẫn duy trì từ năm 2005 - 2012, trong đó tỷ lệ bệnh nhân bệnh thận mạn giai đoạn 3 tăng nhanh từ 4,5\% lên $6,0 \%{ }^{(1)}$. 